\title{
Correction: Stunting is not a synonym of malnutrition
}

\author{
C. Scheffler $\mathbb{1}^{1} \cdot$ M. Hermanussen ${ }^{2} \cdot$ B. Bogin $\mathbb{1}^{3} \cdot$ D. S. Liana ${ }^{4} \cdot$ F. Taolin ${ }^{5} \cdot$ P. M. V. P. Cempaka ${ }^{5}$ M. Irawan ${ }^{5} \cdot$ \\ L. F. Ibbibah ${ }^{5} \cdot$ N. K. Mappapa ${ }^{4} \cdot$ M. K. E. Payong ${ }^{4} \cdot$ A. V. Homalessy ${ }^{4} \cdot$ A. Takalapeta ${ }^{4}$ S. Apriyanti ${ }^{4}$. \\ M. G. Manoeroe ${ }^{4} \cdot$ F. R. Dupe ${ }^{4} \cdot$ R. R. K. Ratri ${ }^{4} \cdot$ S. Y. Touw ${ }^{4} \cdot$ P. V. $K^{4} \cdot$ B. J. Murtani ${ }^{4} \cdot$ R. Nunuhitu ${ }^{4} \cdot$ R. Puspitasari ${ }^{6}$. \\ I. K. Riandra ${ }^{7}$ A. S. Liwan $^{7}$ - P. Amandari ${ }^{7}$ A. A. I. Permatasari ${ }^{7}$ - M. Julia ${ }^{8}$ - J. Batubara ${ }^{9,10}$ - A. Pulungan ${ }^{10,11}$
}

Published online: 21 October 2019

(C) The Author(s), under exclusive licence to Springer Nature Limited 2019

\section{Correction to: European Journal of Clinical Nutrition} https://doi.org/10.1038/s41430-019-0439-4

Since publication of the original article, the authors realised there was a small error in the affiliation of author A.
Pulungan. This affiliation has now been corrected in both HTML and PDF versions of the article.
M. Hermanussen

michael.hermanussen@gmail.com

1 University of Potsdam, Human Biology, 14469

Potsdam, Germany

2 Aschauhof, 24340 Altenhof, Germany

3 Health and Wellbeing Global Challenge, School of Sport, Exercise \& Health Sciences, Loughborough University, Leicestershire LE11 3TU, UK

4 Medical Faculty Nusa Cendana University, Kupang-East Nusa Tenggara, Kupang, Indonesia

5 East Nusa Tenggara Indonesian Society of Pediatrician, KupangEast Nusa Tenggara, Kupang, Indonesia
6 School of Medicine, University of Sumatera Utara, Medan, Sumatera Utara, Indonesia

7 Child Health Department Udayana University Sanglah Hospital, Bali, Indonesia

8 Department of Child Health, Faculty of Medicine, Public Health and Nursing, Universitas Gadjah Mada, Yogyakarta, Indonesia

9 Department of Child Health, Medical School, University of Indonesia, Jakarta 10430, Indonesia

10 Indonesian Pediatric Society, Jakarta, Indonesia

11 Department of Child Health University of Indonesia, Dr. Cipto Mangunkusumo Hospital, Jakarta 10430, Indonesia 